\title{
Ocular rhinosporidiosis mimicking conjunctival squamous papilloma in Kenya - a case report
}

\author{
Stephen Gichuhi ${ }^{1,2^{*}}$, Timothy Onyuma ${ }^{3}$, Ephantus Macharia ${ }^{4}$, Joy Kabiru4 ${ }^{4}$ Alain M'bongo Zindamoyen ${ }^{4}$,
} Mandeep S Sagoo ${ }^{5,6}$ and Matthew J Burton ${ }^{2,5}$

\begin{abstract}
Background: Ocular rhinosporidiosis is a chronic granulomatous infection caused by a newly classified organism that is neither a fungus nor bacterium. It often presents as a benign conjunctival tumour but may mimic other ocular conditions. It is most often described in India. In Africa cases have been reported from South Africa, Kenya, Tanzania, Malawi, Uganda, Congo and Ivory Coast.

Case presentation: A 54 year old man was seen in Kenya with a lesion that resembled a conjunctival papilloma. We report resemblance to conjunctival papilloma and the result of vital staining with $0.05 \%$ Toluidine Blue.

Conclusion: Ocular rhinosporidiosis occurs in East Africa. It may resemble conjunctival squamous papilloma. Vital staining with $0.05 \%$ Toluidine blue dye did not distinguish the two lesions well.
\end{abstract}

Keywords: Ocular rhinosporidiosis, Rhinosporidium seeberi, Conjunctival papilloma, Toluidine-blue, Africa

\section{Background}

Rhinosporidiosis is a chronic granulomatous infection of the mucous membranes (nasal, oral, ocular and rectal) caused by Rhinosporidium seeberi [1]. This is an unusual unicellular pathogen that is difficult to culture and whose taxonomic classification has been controversial. It has been variously hypothesized to be a cyanobacterium (prokaryote), a eukaryotic Mesomycetozoa or a fungus [2]. Currently it is domiciled in the Mesomycetozoea class (also known as the DRIP clade, or Ichthyosporea). The term Mesomycetozoea derives from "Meso-" (in the middle of), "-myceto-" (fungi) and "-zoea" (animals). This is a heterogeneous group of microorganisms at the animal-fungal boundary. The Mesomycetozoea are a small group of protists, which are mostly parasites of fish and other animals.

Rhinosporidiosis affects both adults and children and is commonly seen in otolaryngology. The largest reported case series of rhinosporidiosis consisting of 462 cases in India found that the disease mainly occurs in the nose and nasopharynx (81.1\%) while the eye was affected in $14.2 \%$ [3]. Another series of 34 cases from

\footnotetext{
* Correspondence: sgichuhi@uonbi.ac.ke

${ }^{1}$ Department of Ophthalmology, University of Nairobi, Nairobi, Kenya

${ }^{2}$ London School of Hygiene and Tropical Medicine, London, UK

Full list of author information is available at the end of the article
}

India also found nasal and nasopharyngeal involvement in $85 \%$ while the eye was affected in $9 \%$ of cases [4]. A case involving multiple parts of the body; the nares, multiple areas of the skin, the external urethral meatus, glans of penis and the perineum has been reported in India [5].

Ocular rhinosporidiosis affecting the conjunctiva was first described in India in 1912 [6]. Currently most published reports on rhinosporidiosis of the eye have been reported from Asia mainly from India, Sri Lanka, Nepal and Bangladesh. In Africa it has been reported in South Africa, Malawi, Zambia, Kenya, Uganda, Tanzania, Congo, Ivory Coast, and Cameroon [7-13]. None of the cases in Africa were initially diagnosed as ocular rhinosporidiosis, perhaps a sign of its rarity.

How the disease is acquired remains an enigma. Rhinosporidiosis has been associated with migrants from endemic areas [14-16]. Although it is an infectious disease, as lesions are always associated with the presence of the pathogen, there is limited data on how it might be transmitted [15]. It is presumed to be acquired through traumatized nasal mucosa and spread to other sites by autoinoculation. As most rhinosporidiosis lesions arise from the nose, it is feasible that ocular involvement may occur by spreading from the nose through the lacrimal
C Biomed Central

(C) 2014 Gichuhi et al.; licensee BioMed Central Ltd. This is an Open Access article distributed under the terms of the Creative Commons Attribution License (http://creativecommons.org/licenses/by/2.0), which permits unrestricted use, distribution, and reproduction in any medium, provided the original work is properly credited. 

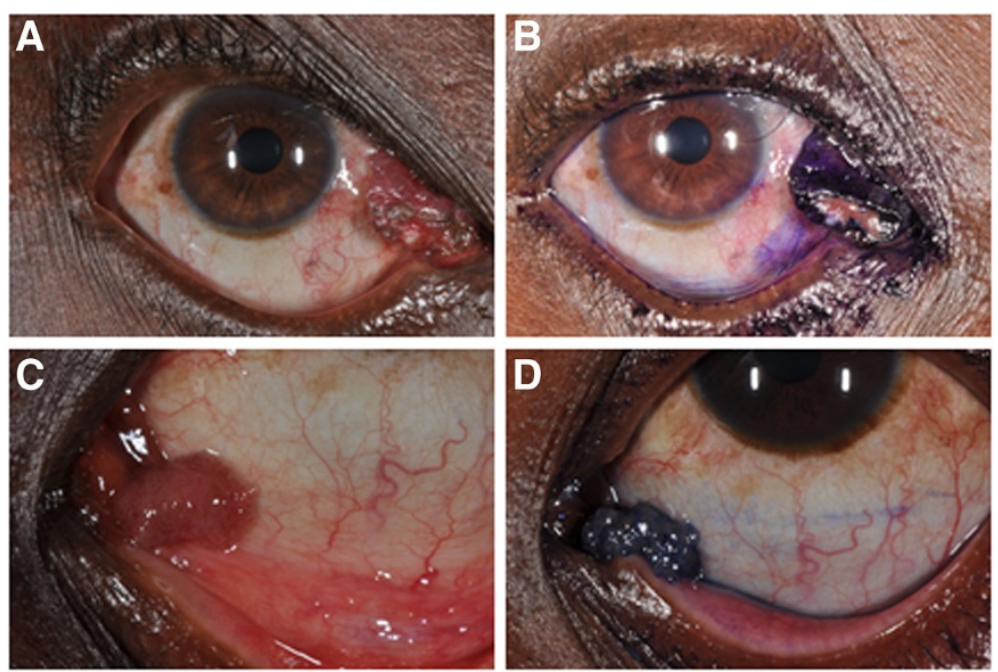

Figure 1 Pre-operative clinical photographs. A \& B - shows the ocular rhinosporidiosis lesion in the region of the right medial canthus.

$\mathbf{C} \& \mathbf{D}$ - shows squamous papilloma in the left medial canthus area from another patient for comparison. Both lesions are shown before and after vital staining with $0.05 \%$ Toluidine Blue.

sac to the plica of the conjunctiva. This hypothesis is however unproven.

Ocular rhinosporidium most often presents as a polypoid mass of the palpebral conjunctiva [17]. It may also present as a lacrimal sac diverticulum [18], recurrent chalazion [19], conjunctival cyst [20], chronic follicular conjunctivitis in contact lens wearers [21], peripheral keratitis [22], scleral melting [23], ciliary staphyloma [24] or simulate a tumour of the eyelid [25] or periorbital skin [26]. Large conjunctival lesions may cause mechanical ectropion [27]. Lacrimal sac disease may present with bloody tears [16].

In a series of 63 cases from India that included nasal, nasopharyngeal and ocular disease, routine haematology tests did not show any abnormality and while cytology

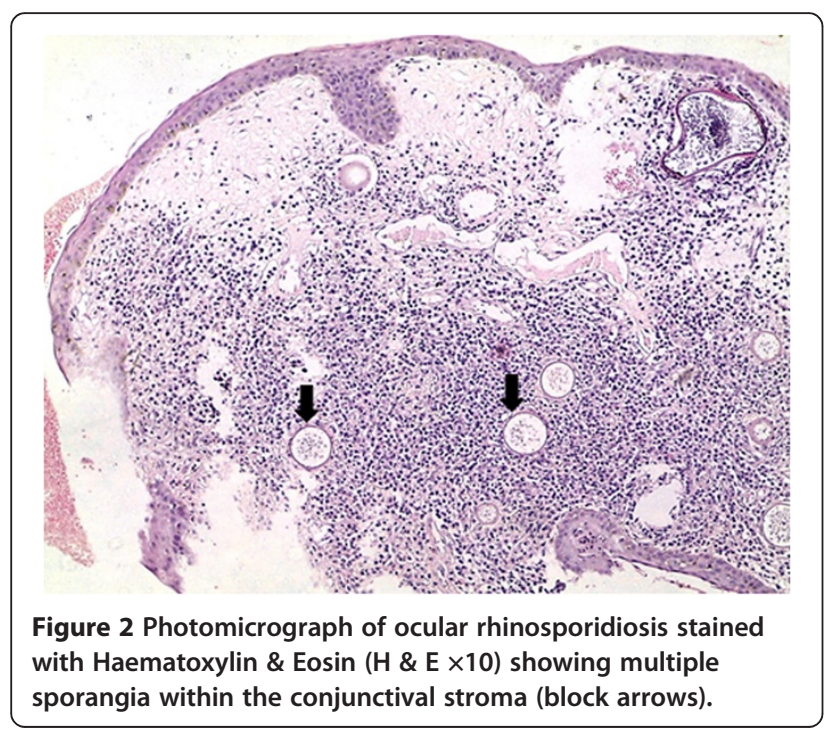

of smears obtained via fine needle aspiration or cytology has a role in diagnosis, the mainstay remains histology [28]. Vital staining with Toluidine blue has been described for diagnosis of conjunctival tumours but not for rhinosporidiosis [29].

The treatment is surgical excision with or without cautery at the base and recurrence is described as rare [30]. Scleral melting may be treated with a tectonic corneal graft [31]. There are reports that the following agents are effective in vivo: imidocarb diproprionate, diminazine aceturate, cycloserine, dapsone, trimethoprim-suphadiazine, ketoconazole, sodium stibogluconate, and amphotericin B [32]. Dapsone is the most commonly reported drug and combination therapy to prevent drug resistance is recommended. A laboratory study in India found that biocides

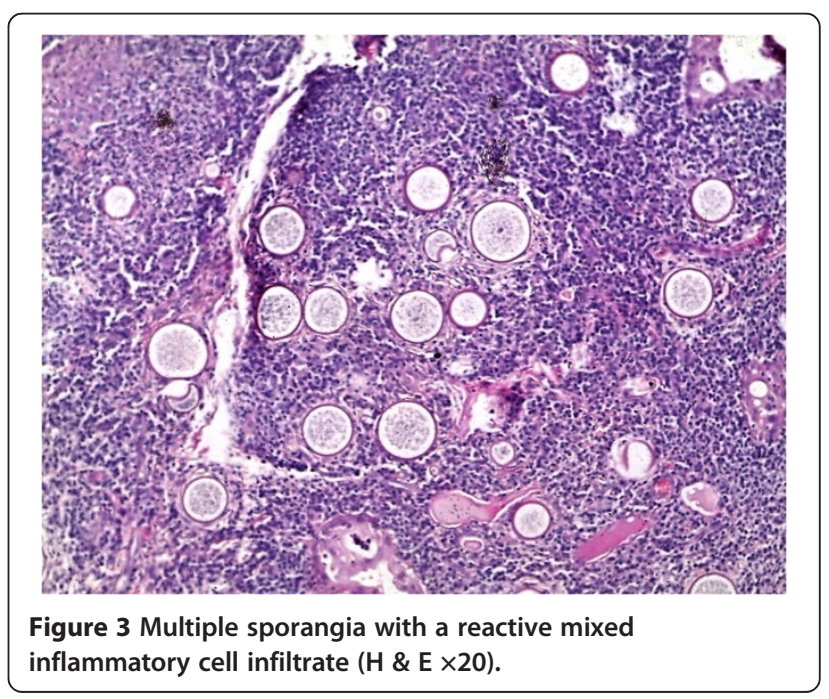




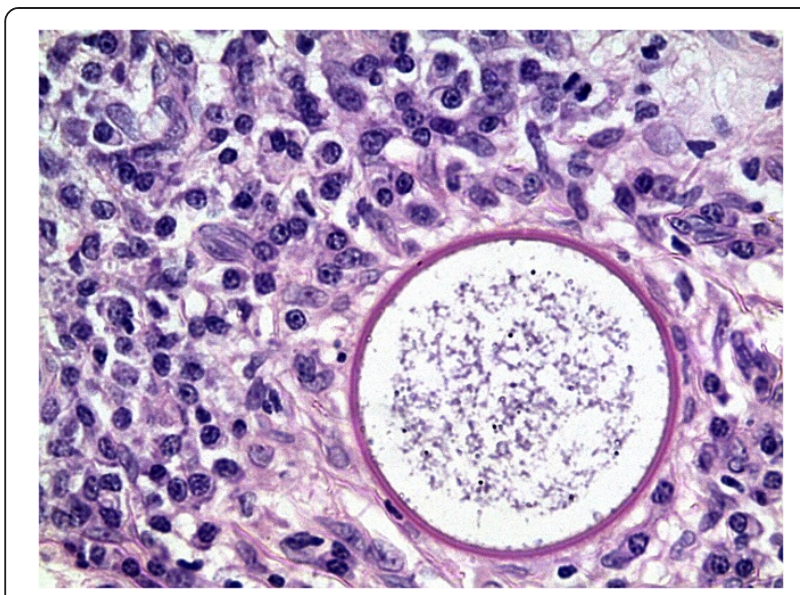

Figure 4 Sporangium at higher magnification filled with endoconidia and surrounded by plasma cells and lymphocytes (H \& E ×40). including hydrogen peroxide, glutaraldehyde, chloroxylenol, chlorhexidine, cetrimide, thimerosal, $70 \%$ ethanol, iodine in $70 \%$ ethanol, $10 \%$ formalin, povidone-iodine, sodium azide and silver nitrate caused metabolic inactivation with or without altered structural integrity of the endoconidia of Rhinosporidium seeberii but no human trials have been reported [33]. Human anti-rhinosporidial antibody is not directly protective against the endoconidia [34].

\section{Case presentation}

A 54-year-old male presented to the eye clinic at the PCEA Kikuyu Hospital on the outskirts of Nairobi with a 16 month history of a painless lump on the surface of the right eye. Concerned about the appearance, he attributed the lesion to a foreign body that entered that eye while he was trimming a hedge.

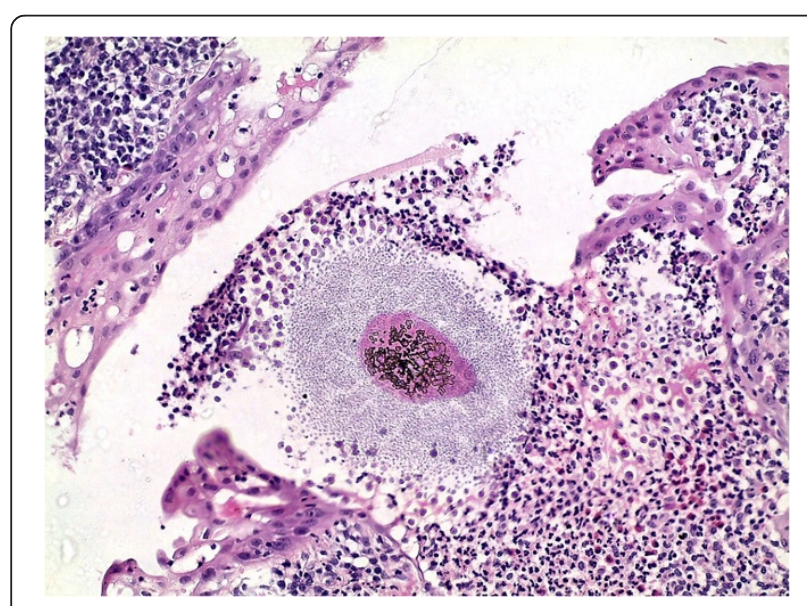

Figure 5 Burst sporangium with discharged microsporangia surrounded by an inflammatory cell infiltrate ( $H \& E \times 40)$.

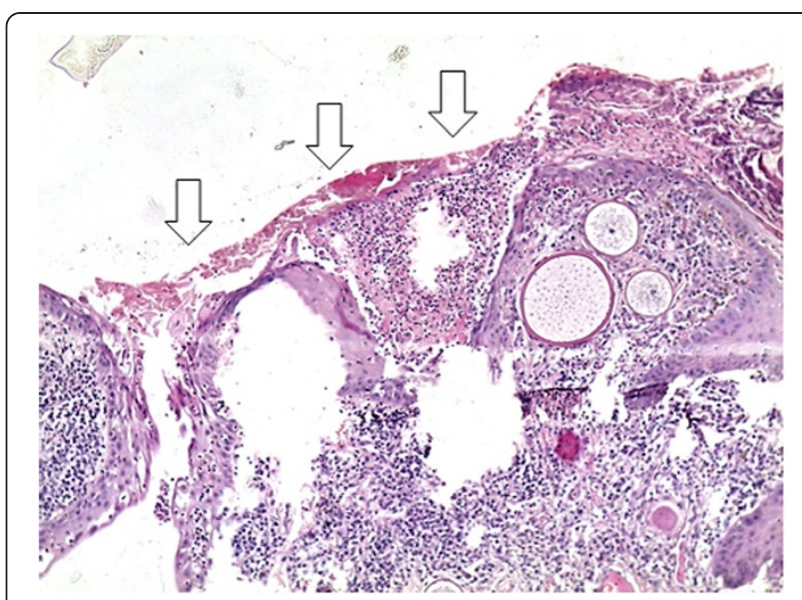

Figure 6 Ulcerated surface epithelium (open arrows) with a fibrin plaque and granulation tissue on the basal side of the ulcer (H \& E ×20).

No other family member or neighbour had a similar disease. Social history included living in Homa Bay district on the shores of Lake Victoria from birth to 18 years age, then Kapsabet, a highland area in the Rift Valley until the age of 26 years, followed by Nairobi. He had resided in a low-income area of Nairobi for the past 11 years. Occupational history included working as a gardener for the last 10 years and a cook for 5 years prior to that. Although he grew up in a lakeside area, he had not dived or swum in stagnant water in the recent past.

On examination he had a pedunculated $6 \times 11 \mathrm{~mm}$ wide fleshy mass at the medial canthus of the right eye (Figure 1), which was pink with some intrinsic pigmentation. It had a papilliform surface with vascular tufts and some epithelial ulceration. There was no discharge or conjunctival injection. The mass was not attached to the lid but arose from the plica semilunaris. On vital staining with $0.05 \%$ Toluidine Blue it was coloured deep blue except at the ulcerated surface, similar to the staining of a papilloma. The clinical diagnosis was of conjunctival papilloma and surgical excision under local anaesthetic was undertaken.

Histological analysis revealed multiple sporangia in the conjunctival stroma, an ulcerated squamous epithelium covered by a fibrin plaque whose underlying tissue showed granulomatous tissue, mixed inflammatory cells

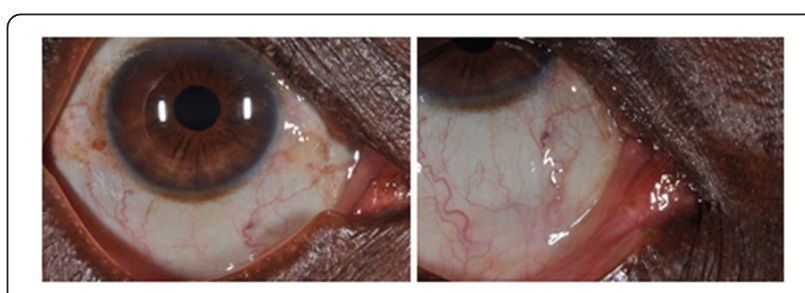

Figure 7 Post-operative photographs showing no recurrence 6 months after excision of ocular rhinosporidiosis. 
with lymphocytes showing a maturation spectrum and numerous thick walled sporangia filled with nucleated basophilic endoconidia (Figures 2, 3, 4, 5 and 6). A diagnosis of ocular rhinosporidiosis was made.

There was no recurrence 6 months after excision was performed (Figure 7).

\section{Conclusions}

Ocular rhinosporidiosis occurs in East Africa. It may resemble conjunctival squamous papilloma. Although toluidine blue has been used as a vital stain of conjunctival lesions, in this case, it was unable to distinguish between an infective and neoplastic cause.

\section{Consent}

Written informed consent was obtained from the patient for publication of this case report and any accompanying images. A copy of the written consent is available for review by the Editor of this journal.

\section{Competing interests}

The authors declare that they have no competing interests.

\section{Authors' contributions}

SG first evaluated the case, took clinical photographs and conceived the report idea. EM performed the excision surgery. TO performed the histopathological assessment and made the diagnosis. JK reviewed the case on follow up. AMZ coordinated patient and institutional consent for publication of this clinical material. MSS and MJB evaluated the clinical and histopathology photographs. All authors read and approved the final manuscript.

\section{Acknowledgements}

Dr. E.W. Walong of the Department of Human Pathology, University of Nairobi for taking the histology photographs.

\section{Author details}

'Department of Ophthalmology, University of Nairobi, Nairobi, Kenya.

${ }^{2}$ London School of Hygiene and Tropical Medicine, London, UK.

${ }^{3}$ Department of Pathology, MP Shah Hospital, Nairobi, Kenya. ${ }^{4}$ PCEA Kikuyu Hospital Eye Unit, Kikuyu, Kenya. ${ }^{5}$ Moorfields Eye Hospital, London, UK. ${ }^{6}$ UCL Institute of Ophthalmology, University College London, London, UK.

Received: 1 August 2013 Accepted: 3 April 2014

Published: 8 April 2014

\section{References}

1. Arseculeratne SN: Rhinosporidiosis: what is the cause? Curr Opin Infect Dis 2005, 18(2):113-118.

2. Vilela R, Mendoza L: The taxonomy and phylogenetics of the human and animal pathogen Rhinosporidium seeberi: a critical review. Rev lberoam Micol 2012, 29(4):185-199.

3. Sudarshan V, Goel NK, Gahine R, Krishnani C: Rhinosporidiosis in Raipur, Chhattisgarh: a report of 462 cases. Indian J Pathol Microbiol 2007, 50(4):718-721.

4. Makannavar JH, Chavan SS: Rhinosporidiosis-a clinicopathological study of 34 cases. Indian J Pathol Microbiol 2001, 44(1):17-21.

5. Mallick AA, Majhi TK, Pal DK: Rhinosporidiosis affecting multiple parts of the body. Trop Dr 2012, 42(3):174-175.

6. Duke-Elder S: Diseases of the Outer Eye. Illth edition. St. Louis: Mosby; 1965.

7. Salazar Campos MC, Surka J, Garcia Jardon M, Bustamante N: Ocular rhinosporidiosis. S Afr Med J 2005, 95(12):950-952.

8. Pe'er J, Gnessin H, Levinger S, Averbukh E, Levy Y, Polacheck I: Conjunctival oculosporidiosis in east Africa caused by Rhinosporidium seeberi. Arch Pathol Lab Med 1996, 120(9):854-858.
9. Venkataramaiah NR, van Raalte JA, Shabe JK: Rhinosporidiosis in Tanzania. Trop Geogr Med 1981, 33(2):185-187.

10. Kaimbo KW, Parys-Van Ginderdeuren R: Conjunctival rhinosporidiosis: a case report from a Congolese patient. Bull Soc Belge Ophtalmol 2008, 309-310:19-22.

11. Dago-Akribi A, Ette M, Diomande MI, Kioffi Y, Honde M, D'Ordock AF, Beaumel A: Clinico-pathologic aspects of rhinosporidiosis in the Ivory Coast. Report of 9 cases observed over 18 years. Ann Pathol 1993, 13(2):97-99.

12. Naik KG, Shukla SM: Rhinosporidiosis in Zambia. Med J Zambia 1980, 14(5):78-80.

13. Ravisse P, Le Gonidec G, Moliva B: [Report on first 2 cases of rhinosporidiosis in Cameroon]. Bulletin de la Societe de pathologie exotique et de ses filiales 1976, 69(3):222-224.

14. Sood N, Agarwal MC, Gugnani HC: Ocular rhinosporidiosis: a case report from Delhi. J Infect Dev Ctries 2012, 6(11):825-827.

15. Arseculeratne $\mathrm{SN}$ : Recent advances in rhinosporidiosis and Rhinosporidium seeberi. Indian J Med Microbiol 2002, 20(3):119-131.

16. Belliveau MJ, Strube YN, Dexter DF, Kratky V: Bloody tears from lacrimal sac rhinosporidiosis. Can J Ophthalmol Can J Ophthalmol 2012, 47(5):e23-e24.

17. Ghosh AK, De Sarkar A, Bhaduri G, Datta A, Das A, Bandyopadhyay A: Ocular rhinosporidiosis. J Indian Med Assoc 2004, 102(12):732-764.

18. Varshney S, Bist SS, Gupta P, Gupta N, Bhatia R: Lacrimal sac diverticulum due to Rhinosporidiosis. Indian j otolaryngol head and neck surgery: official publication of the Assoc Otolaryngologists of India 2007, 59(4):353-356.

19. Mukhopadhyay S, Shome S, Bar PK, Chakrabarti A, Mazumdar S, De A, Sadhukhan K, Bala B: Ocular rhinosporidiosis presenting as recurrent chalazion. Int Ophthalmol 2012, 1-3. PMID 22986579.

20. Lavaju P, Arya SK, Kumar B, Upadhaya P: Conjunctival rhinosporidiosis presenting as a cystic mass-an unusual presentation. Nepal J Ophthalmol: NEPJOPH 2010, 2(2):157-159.

21. Suh LH, Barron J, Dubovy SR, Gaunt ML, Ledee DR, Miller D, Fell JW, Forster RK: Ocular rhinosporidiosis presenting as chronic follicular conjunctivitis in a contact lens wearer. Arch Ophthalmol 2009, 127(8):1076-1077.

22. Bhomaj S, Das JC, Chaudhuri Z, Bansal RL, Sharma P: Rhinosporidiosis and peripheral keratitis. Ophthalmic Surg Lasers 2001, 32(4):338-340.

23. De Doncker RM, de Keizer RJ, Oosterhuis JA, Maes A: Scleral melting in a patient with conjunctival rhinosporidiosis. Br J Ophthalmol 1990, 74(10):635-637.

24. Talukder AK, Rahman MA, Islam MN, Chowdhury MH: Ciliary staphyloma: very rare sequelae of conjunctival rhinosporiodosis. Mymensingh Med J: MMJ 2004, 13(1):86-87.

25. Sharma KD, Shrivastav JB, Agarwal S: Ocular rhinosporidiosis simulating a tumour. Br J Ophthalmol 1958, 42(9):572-574.

26. Vallarelli AF, Rosa SP, Souza EM: Rhinosporidiosis: cutaneous manifestation. An Bras Dermatol 2011, 86(4):795-796.

27. Mandal SK, Bhakta A, Mandal A, Biswas BK: Giant mass conjunctival rhinosporidiosis causing severe mechanical ectropion. J Indian Med Assoc 2012, 110(5):328-329.

28. Sinha A, Phukan JP, Bandyopadhyay G, Sengupta S, Bose K, Mondal RK, Choudhuri MK: Clinicopathological study of rhinosporidiosis with special reference to cytodiagnosis. J cyto//Indian Acad Cytologists 2012, 29(4):246-249.

29. Romero IL, Barros Jde N, Martins MC, Ballalai PL: The use of $1 \%$ toluidine blue eye drops in the diagnosis of ocular surface squamous neoplasia. Cornea 2013, 32(1):36-39.

30. Mithal C, Agarwal P, Mithal N: Ocular and adnexal rhinosporidiosis : the clinical profile and treatment outcomes in a tertiary eye care centre. Nepal J Ophthalmol 2012, 4(1):45-48.

31. Jacob P, Rose JS, Hoshing A, Chacko G: Tectonic corneal graft for conjunctival rhinosporidiosis with scleral melt. Indian J Ophthalmol 2011, 59(3):251-253.

32. Arseculeratne SN: Chemotherapy of Rhinosporidiosis: a Review. J Infect Dis Antimicrob Agents 2009, 26(1):21-27.

33. Arseculeratne SN, Atapattu DN, Balasooriya P, Fernando R: The effects of biocides (antiseptics and disinfectants) on the endospores of Rhinosporidium seeberi. Indian J Med Microbiol 2006, 24(2):85-91.

34. Arseculeratne SN, Atapattu DN, Eriyagama NB: Human anti-rhinosporidial antibody does not cause metabolic inactivation or morphological damage in endospores of Rhinosporidium seeberi, in vitro. Indian J Med Microbiol 2005, 23(1):14-19.

doi:10.1186/1471-2415-14-45

Cite this article as: Gichuhi et al:: Ocular rhinosporidiosis mimicking conjunctival squamous papilloma in Kenya - a case report. BMC Ophthalmology 2014 14:45. 